\title{
Polishing techniques for MEGARA pupil elements optics
}

\author{
R. Izazaga ${ }^{1, *}$, E. Carrasco ${ }^{1}$, D. Aguirre ${ }^{3}$, A. Salas ${ }^{1,2}$, A. Gil de Paz ${ }^{4}$, J. Gallego ${ }^{4}$, J. Iglesias ${ }^{5}$, J. M. \\ Arroyo $^{1}$, M. Hernández ${ }^{1}$, N. López ${ }^{1}$, V. López ${ }^{1}$, J.T. Quechol ${ }^{1}$, M. F. Salazar ${ }^{1}$, C. Carballo ${ }^{1}$, E. \\ Cruz $^{1}$, J. Arriaga ${ }^{1}$, J. A. De la Luz ${ }^{1}$, A. Huepa ${ }^{1}$, G. L. Jaimes ${ }^{1}$, J. Reyes ${ }^{1}$, and MEGARA team. \\ ${ }^{1}$ Instituto Nacional de Astrofísica, Óptica y Electrónica (INAOE, Mexico) \\ ${ }^{2}$ Universidad Autónoma de Sinaloa (UAS, Mexico) \\ ${ }^{3}$ Centro de Ciencias Avanzadas y Desarrollo Tecnológico (CCADET-UNAM, Mexico) \\ ${ }^{4}$ Universidad Complutense de Madrid (UCM, Spain) \\ ${ }^{5}$ Instituto de Astrofísica de Andalucía (IAA-CSIC, Spain) \\ *izazagax@gmail.com
}

\begin{abstract}
MEGARA (Multi-Espectrógrafo en GTC de Alta Resolución para Astronomía) is the new integral-field and multi-object optical spectrograph for the $10.4 \mathrm{~m}$ Gran Telescopio Canarias.. It will offer RFwhm $\sim 6,000,12,000$ and 18,700 for the low, mid- and high-resolution, respectively in the wavelength range 3650-9700 $\AA$. The dispersive elements are volume phase holographic (VPH) gratings, sandwiched between two flat Fused Silica windows of high optical precision in large apertures. The design, based in VPHs in combination with Ohara PBM2Y prisms allows to keep the collimator and camera angle fixed. Seventy three optical elements are being built in Mexico at INAOE and CIO. For the low resolution modes, the VPHs windows specifications in irregularity is 1 fringe in $210 \mathrm{~mm} \times 170 \mathrm{~mm}$ and 0.5 fringe in $190 \mathrm{~mm} \times 160 \mathrm{~mm}$. for a window thickness of $25 \mathrm{~mm}$. For the medium and high resolution modes the irregularity specification is 2 fringes in $220 \mathrm{~mm} \times 180 \mathrm{~mm}$ and 1 fringe in $205 \mathrm{~mm} \times 160 \mathrm{~mm}$, for a window thickness of $20 \mathrm{~mm}$. In this work we present a description of the polishing techniques developed at INAOE optical workshop to fabricate the 36 Fused Silica windows and 24 PBM2Y prisms that allows us to achieve such demanding specifications. We include the processes of mounting, cutting, blocking, polishing and testing.
\end{abstract}

Keywords: MEGARA, spectrograph, optical fabrication, optical testing, polishing.

\section{INTRODUCTION}

MEGARA, is the acronym of Multi-Espectrógrafo en GTC de Alta Resolución para Astronomía. It is the new generation optical spectrograph of the $10.4 \mathrm{~m}$ Gran Telescopio CANARIAS. The instrument is being built by a Consortium of public institutions led by the Universidad Complutense de Madrid and that also includes the Instituto Nacional de Astrofísica, Óptica y Electrónica (INAOE, Mexico), the Instituto de Astrofísica de Andalucía and the Universidad Politécnica de Madrid. MEGARA is a versatile spectrograph that provides both Integral Field Unit (IFU) and Multi-Object Spectroscopy (MOS) capabilities in resolutions RFwh $\sim 6,000,12,000$ and 18,700 for the low-, mid- and high-resolution, respectively in the visible. . The field-of-view of the IFU is $12.5 \times 11.3 \operatorname{arcsec}^{2}$ while a total of 92 objects can be observed simultaneously with the MOS mode within an area of $3.5 \times 3.5 \mathrm{arcmin}^{2}$. At the end of the MEGARA fiber link the fibers are arranged in two curved but telecentric pseudo-slits, one for the IFU and one for the MOS. The light from these fibers is dispersed by the MEGARA spectrograph, which is a fixed-angle collimatorcamera system. The $\mathrm{f} / 3$ collimator, formed by one singlet and two doublets, has an as-built focal length of $484.5 \mathrm{~mm}$. The $\mathrm{f} / 1.5$ camera, composed by two doublets and three singlets has an as-built focal length of 245.8 $\mathrm{mm}$.

MEGARA provides 18 spectral configurations in the wavelength range of $670-980 \mathrm{~nm}$. Six for low resolution Rfwhm $\sim 6,000$ (LR). Twelve for medium resolution Rғwнm $\sim 12,000$ (MR). Four for in high resolution RFwhm $\sim 18,700$ (HR). To have these configurations 60 pupil optical elements are required, 36 windows: 12 for 
LR, 20 MR, 4 for HR; and 24 prisms: 20 for MR and 4 for HR. These optical elements are being fabricated at INAOE optical workshop. . The dimensions of the of VPHs windows are $220 \mathrm{~mm} \times 180 \mathrm{~mm} \times 30 \mathrm{~mm}$ for LR, and $240 \mathrm{~mm}$ x $190 \mathrm{~mm}$ x $25 \mathrm{~mm}$ for MR and HR, with similar dimensions for the MR and HR prisms apertures. The specification for surface irregularity are very demanding, 0.5 fringes in the central zone for LR windows, and 1 fringes in the central zone for MR and HR windows, the same specification applies for prisms elements. Besides that, the scratch and dig requirements are 40/20 for the coated surfaces, according to MIL13830 norm.

An overview of the MEGARA project is presented by Gil de Paz et al. [1]. The manufacturing process is described by Carrasco et al. [2]. Different MEGARA subsystems are discussed by Castillo et al. [3], Ferrusca et al. [4], Ortíz et al. [5], García-Vargas et al. [6] and Pérez-Calpena et al. [7]. Specific processes in the optical fabrication are briefly described by Izazaga et al. [8].

In section 2 we describe the initial tasks before the polishing process, we describe the procedure for flat windows and prisms blanks. In section 3 the grinding and polishing processes are described. Finally, optical testing is described and some conclusions are presented in sections 4 and 5 respectively.

\section{INITIAL TASKS BEFORE THE POLISHING PROCESS}

\subsection{Cutting}

The fabrication process starts with the cutting machine. The Ohara Fused Silica windows need to be blocked on a circular base. Additional Fused Silica support glass is cut to be fixed around the borders to form a circle. This is required for the polishing process as the polishing machine has rotatory symmetry, see Figure 1(a).
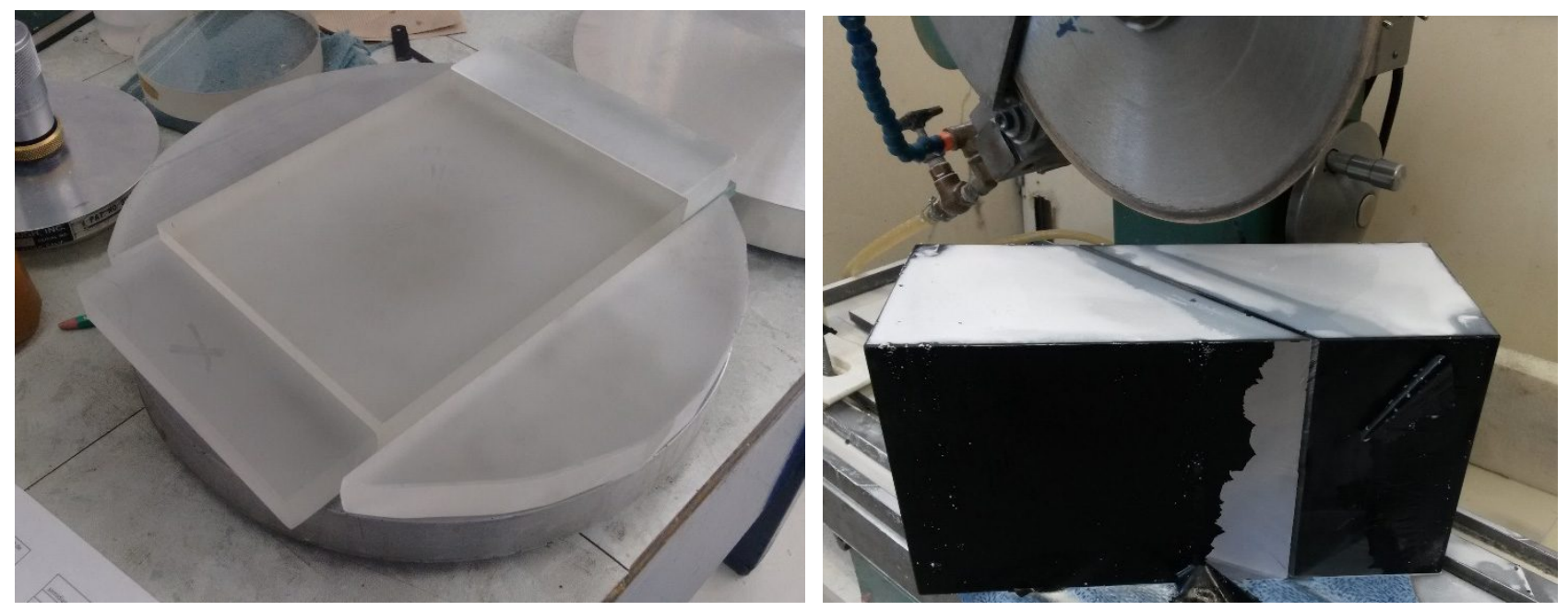

Figure 1. (a) MR window blank with the additional support glasses. (b) PBM2Y blank lateral view, cutting process to obtain a pair of MR prisms.

A PBM2Y parallelepiped blank is available to manufacture each pair of prisms. The first surface is polished before the cutting process, as it is easier to polish the first surface when the blank is in a block form. Due to the dimensions of the PBM2Y blanks the cutting process is carried out in two steps. The machine used is a Strasbaught ${ }^{\mathrm{TM}}$ cutting machine with a diamond disk. The blank is placed on a linear bench to keep the diamond disk rotating while the block is displaced linearly, see Figure 1(b).

Figure 2 shows the first 8 MR prisms., The surface shape given by the diamond disk is irregular. To improve the precision we use a milling machine. The diamond cup wheel was easy to adapt to the hub of this machine. 


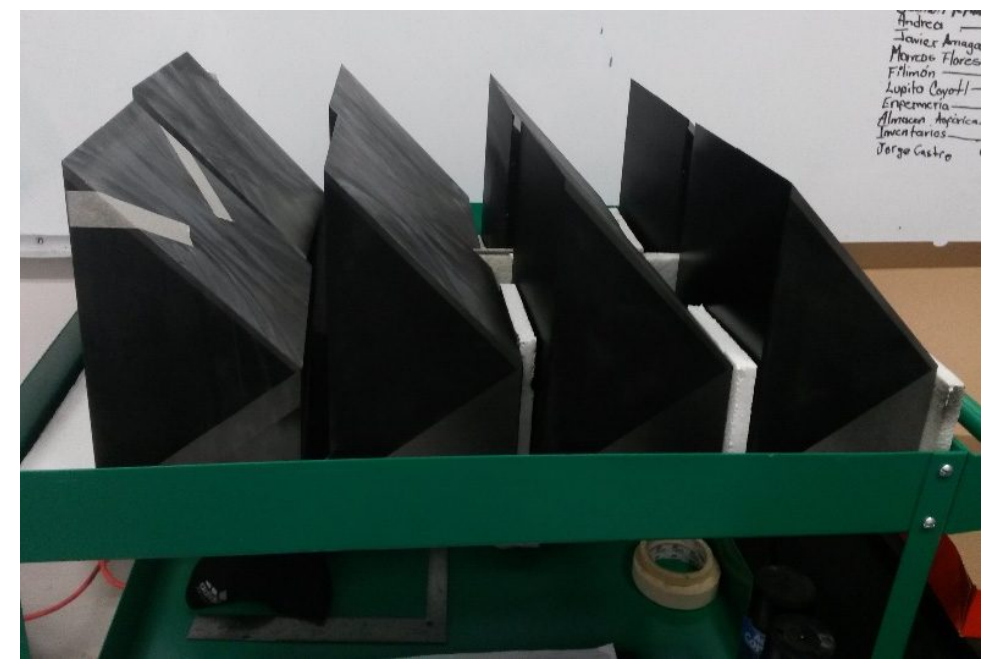

\subsection{Blocking}

Figure 2. MR prisms after the cutting process.

In the case of the windows, the blocking process used was the conventional wax blocking. Hot wax is placed around the window and between the window and the support glasses, see Figure 3(a). The PBM2Y prisms are blocked using the ultraviolet light curing adhesive Norland ${ }^{\circledR}$ NOA 71, see Figure 3(b), a $90^{\circ}$ angle base is used at this step.

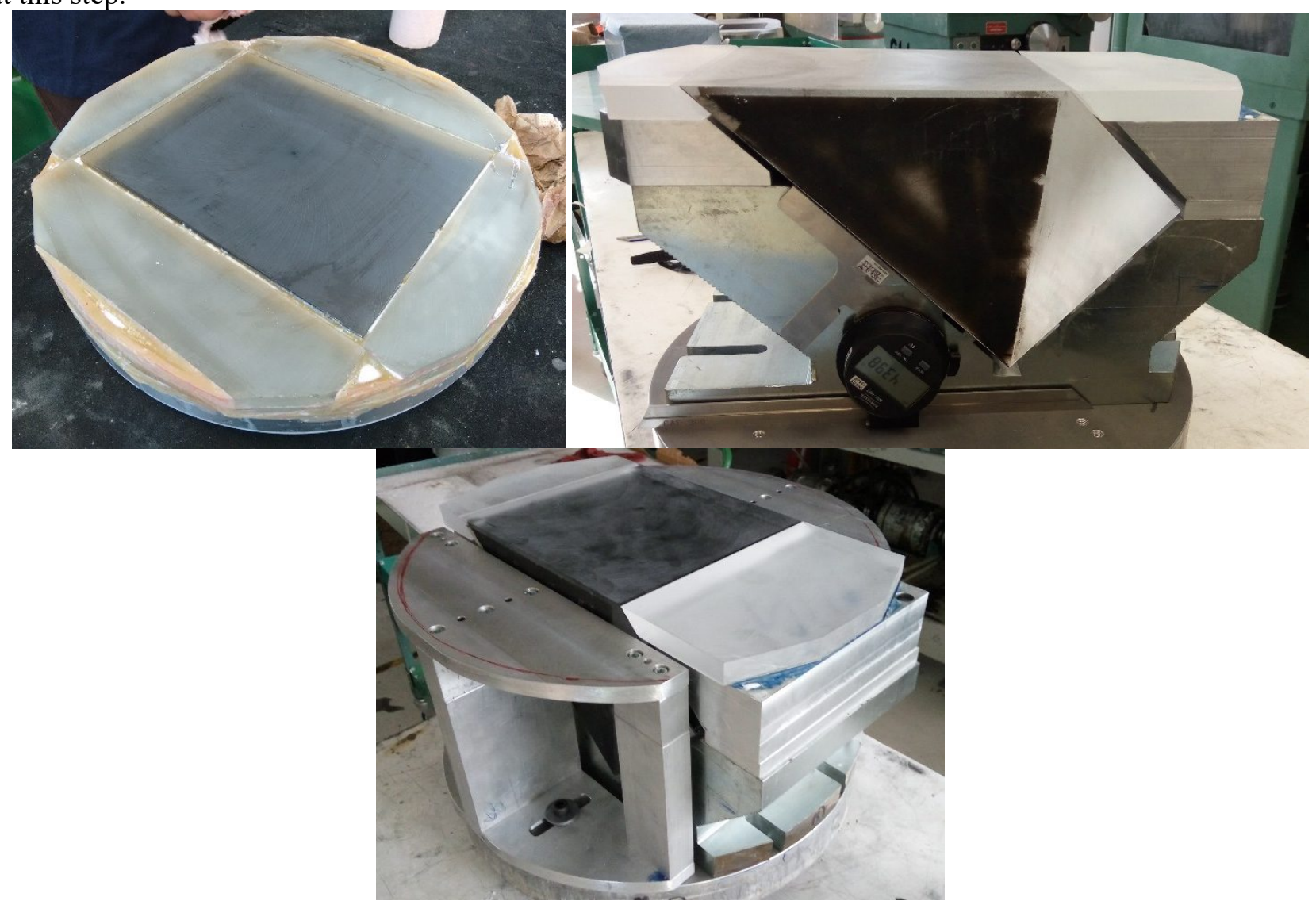

Figure 3. (a) MR window fixed with hot wax. (b) HR prism blocked in a $90^{\circ}$ base, the prism is fixed with UV curing adhesive. (c) Additional lateral aluminum bases to block support glasses. 
To obtain a circular setup for polishing, two lateral aluminum bases were fabricated, in addition to the $90^{\circ}$ base. The bases are used to fix the support glass that are required for the polishing process. These bases are bolted on a circular base.

\section{GRINDING AND POLISHING}

The grinding and polishing processes are carried out in the classical overarm polishing machines (Strasbaugh ${ }^{\circledR}$ 6DA-DC), a rotating axis hold the workpiece and an oscillating arm holds a tool maintaining loose abrasive between both surfaces. Aluminum oxide is used in the grinding process (Microgrit WCA, from Universal Photonics Inc.), in the polishing process, Cerium oxide (Hastilite RS) is used for windows. For the prisms Zirconium oxide (Zirox K). In Figure 4(a) the Strasbaugh polishing machine with a pair of windows being grinded is shown. Figure 4(b) shows a detail of a window being polished with a pitch tool.
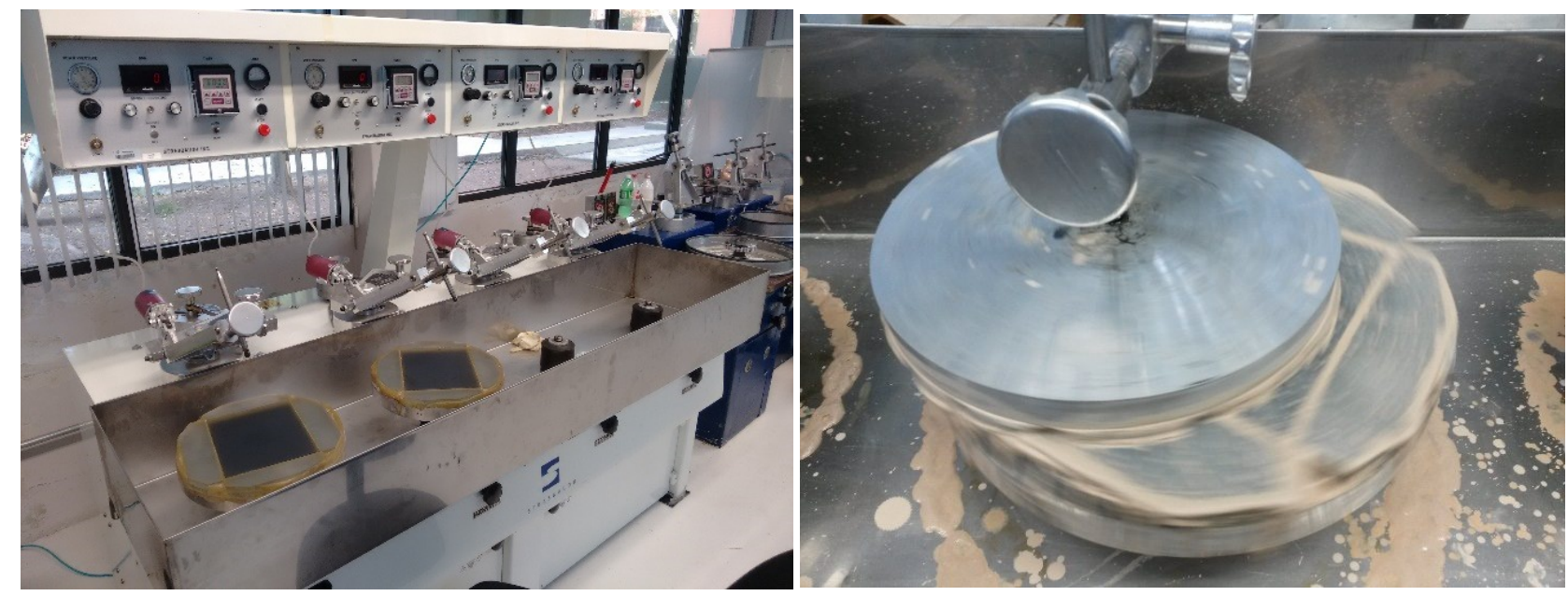

Figure 4. (a) Strasbaugh ${ }^{\circledR}$ polishing machine (6DA-DC-4) in the grinding process for windows. (b) Detail of a window in the polishing process.

The prisms are being polished in the same machine type (6DA-DC-2). Figure 5(a) shows the grinding process for an MR prism, a steel tool is oscillating over the prism. In Figure 5(b) the use of a pitch tool is shown.
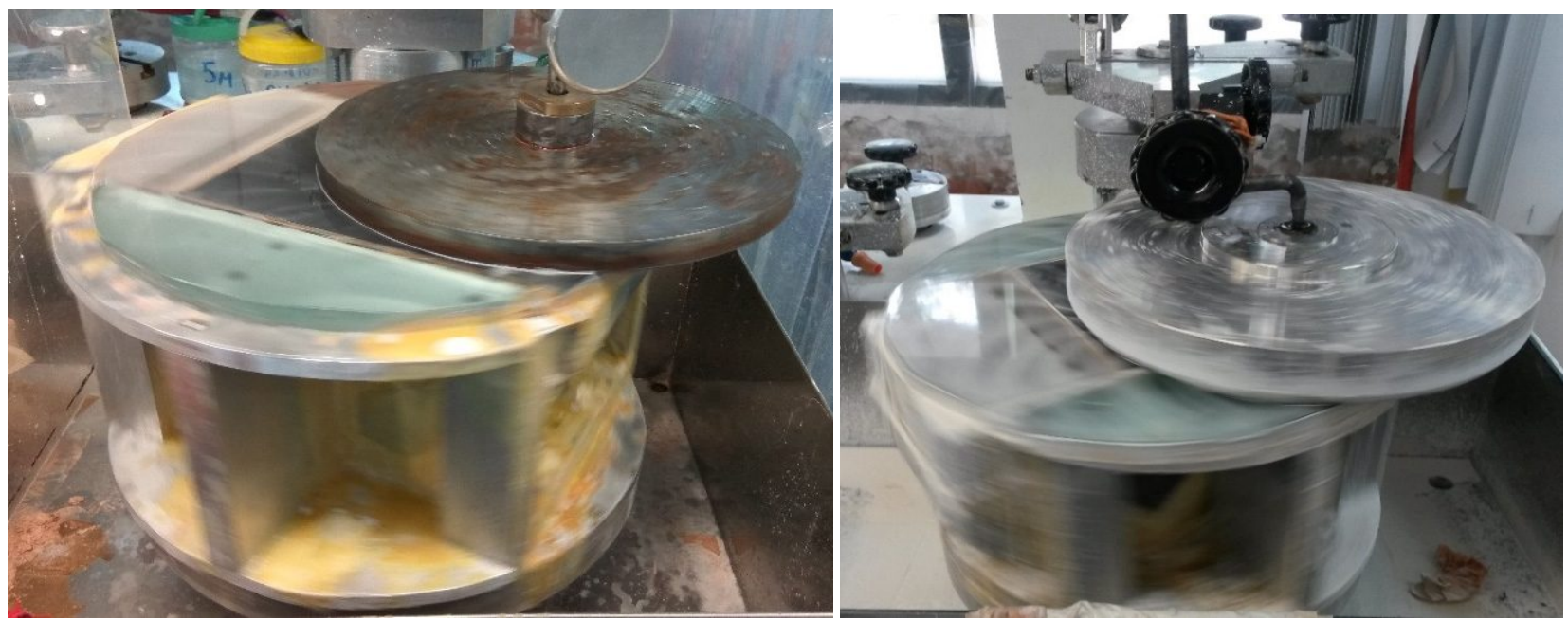

Figure 5. (a) MR prism in the grinding process. (b) MR prism being polished. 


\section{OPTICAL TESTING}

In the final stage of the polishing process, a Newton interferometer is used to verify the surface irregularity, while the window or prism is still blocked in the polishing base, the goal is to obtain 1 fringe of irregularity in both surfaces of an MR window. A reference surface flat (Edmund optics ${ }^{\circledR} 12$ " $P V=\lambda / 20$ ) is placed over the window, and with the help of an extended light source we obtain an interferogram that is analyzed using Durango ${ }^{\circledR}$ software (Diffraction International Inc.). Figure 6 shows this setup. An additional Newton test is carried out when the window is unblocked, to avoid an erroneous analysis due to remaining tensions of the blocking wax.

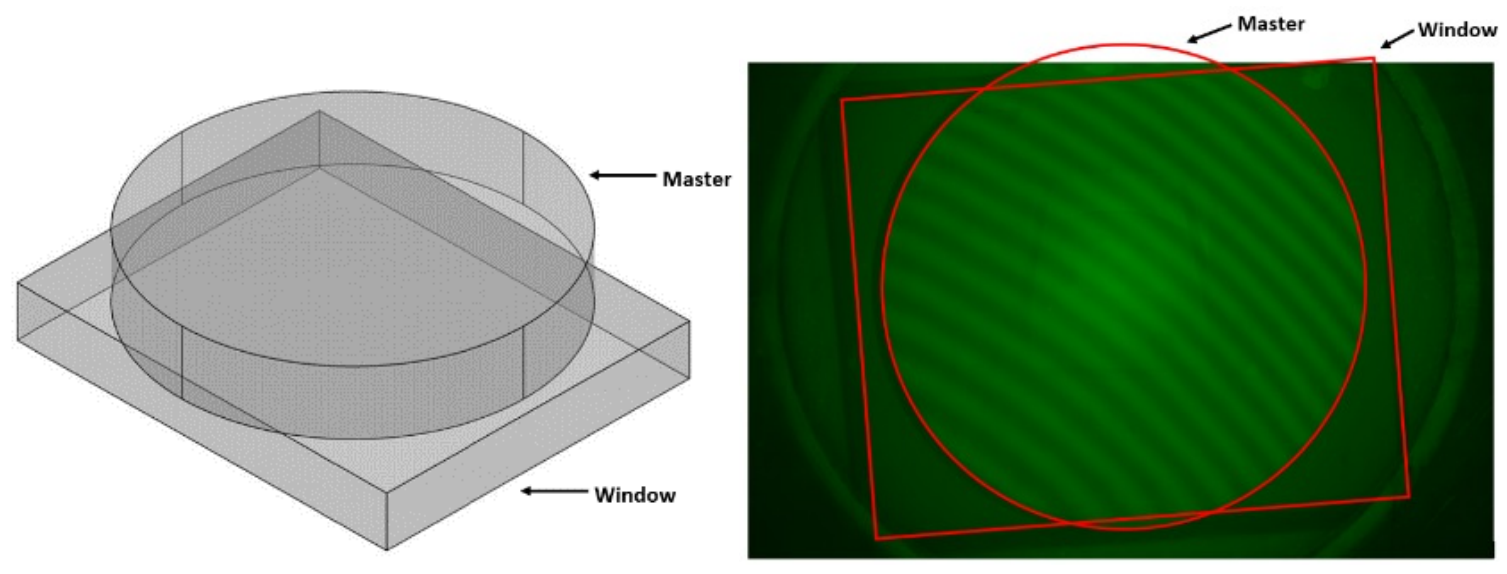

Figure 6. Newton interferometer optical test to verify the surface irregularity of a window.

The analysis of the full apertures of spherical and flat optical surfaces of diameters less than $150 \mathrm{~mm}$ is straightforward as long as the interferometer aperture and its reference spheres have focal ratio suitable for the optics to be tested. However, the increase up to $210 \mathrm{~mm}$ in diameters leads to greater challenges in the area of optical testing.. One of the major challenges is to verify the optical quality of the optical components. To overcome this problem, the technique called sub-aperture stitching method was used. The main idea is to divide the surface under test in small sections for which the interferogram can be obtained with a standard aperture interferometer of $150 \mathrm{~mm}$ or less. The method of stitching, by linking each sub-aperture information, carries out an analysis of the entire surface. This method was used for testing the prisms. INAOE optical testing lab has a Zygo ${ }^{\circledR}$ Fizeau type interferometer, model Mark II, reference flat $P V=\lambda / 20,110 \mathrm{~m}$ of aperture. Figure 7 shows the setup used to obtain subapertures, these subapertures are analyzed using a homemade stitching algorithm that has been compared with other softwares.

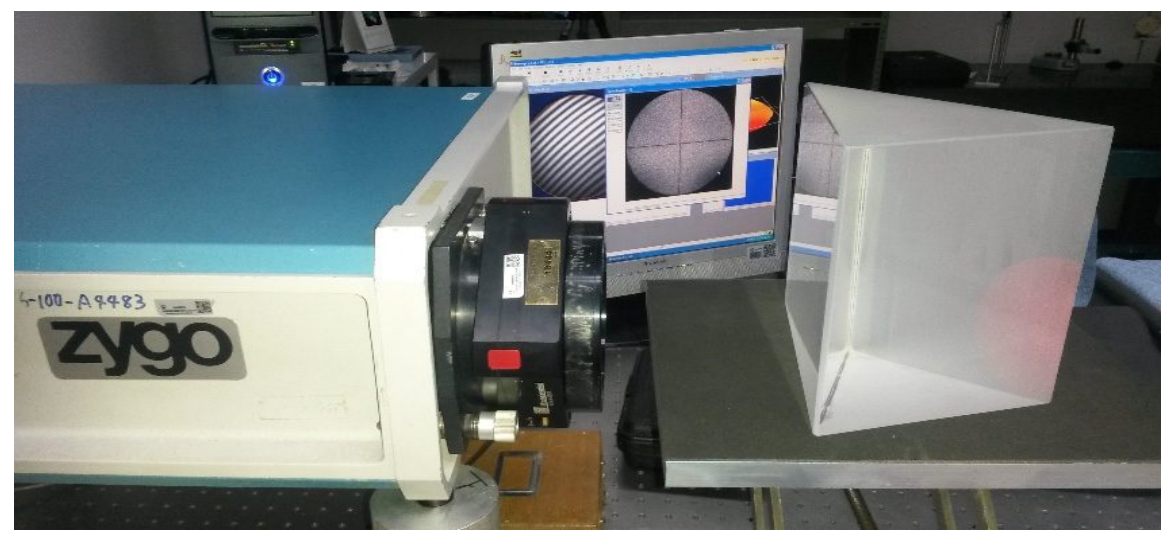

Figure 7. Subaperture stitching method used to verify the surface irregularity of an MR prism. 
Table 1 shows the manufacturing results of MR-UB windows pair, Table 2 shows the results obtained for the HR-I prisms pair.

Table 1. MR-UB windows fabrication results.

\begin{tabular}{|c|c|c|}
\hline \multirow{2}{*}{$\begin{array}{c}\text { MR-UB window } 1 \\
\text { Ohara SK } 3231 \\
\end{array}$} & & \multirow[b]{3}{*}{ Measurement } \\
\hline & & \\
\hline Parameter & Specification & \\
\hline \multicolumn{3}{|l|}{ Surface $A$} \\
\hline $\operatorname{RoC}(\mathrm{mm})$ & Flat & \\
\hline $\begin{array}{l}\text { Irr }(P-V) \text { in used aperture } \\
220 \mathrm{~mm} \times 180 \mathrm{~mm}\end{array}$ & $2 \mathrm{fr}$ & 0.431 \\
\hline $\operatorname{Irr}(\mathrm{P}-\mathrm{V})$ in $205 \times 160 \mathrm{~mm}$ & $1 \mathrm{fr}$ & 0.3635 \\
\hline MIL 13830 SD & $60 / 40$ & $20 / 10$ \\
\hline \multicolumn{3}{|l|}{ Surface B } \\
\hline $\operatorname{RoC}(\mathrm{mm})$ & Flat & \\
\hline $\begin{array}{l}\text { Irr }(\mathrm{P}-\mathrm{V}) \text { in used aperture } \\
220 \mathrm{~mm} \times 180 \mathrm{~mm}\end{array}$ & $2 \mathrm{fr}$ & 0.6855 \\
\hline $\operatorname{Irr}(\mathrm{P}-\mathrm{V})$ in $205 \times 160 \mathrm{~mm}$ & $1 \mathrm{fr}$ & 0.5356 \\
\hline MIL 13830 SD & $60 / 40$ & $20 / 10$ \\
\hline Length $x$ Width $( \pm 0.2) \mathrm{mm}$ & $240 \times 190$ & $240.03 \times 190$ \\
\hline Central thickness* $( \pm 0.1) \mathrm{mm}$ & 20 & 20.01 \\
\hline Wedge (arcmin) & 1 & 0.36 \\
\hline
\end{tabular}

\begin{tabular}{|c|c|c|}
\hline \multirow{2}{*}{\multicolumn{3}{|c|}{$\frac{\text { MR-UB window } 2}{\text { Ohara SK } 3667}$}} \\
\hline & & \\
\hline Parameter & Specification & Measurement \\
\hline \multicolumn{3}{|l|}{ Surface $A$} \\
\hline $\operatorname{RoC}(\mathrm{mm})$ & Flat & \\
\hline $\begin{array}{l}\text { Irr }(\mathrm{P}-\mathrm{V}) \text { in used aperture } \\
220 \mathrm{~mm} \times 180 \mathrm{~mm}\end{array}$ & $2 \mathrm{fr}$ & 0.4534 \\
\hline $\operatorname{Irr}(P-V)$ in $205 \times 160 \mathrm{~mm}$ & $1 \mathrm{fr}$ & 0.4053 \\
\hline MIL 13830 SD & $60 / 40$ & $20 / 10$ \\
\hline \multicolumn{3}{|l|}{ Surface B } \\
\hline $\operatorname{RoC}(\mathrm{mm})$ & Flat & \\
\hline $\begin{array}{l}\text { Irr }(\mathrm{P}-\mathrm{V}) \text { in used aperture } \\
220 \mathrm{~mm} \times 180 \mathrm{~mm}\end{array}$ & $2 \mathrm{fr}$ & 0.3724 \\
\hline $\operatorname{Irr}(P-V)$ in $205 \times 160 \mathrm{~mm}$ & $1 \mathrm{fr}$ & 0.2957 \\
\hline MIL 13830 SD & $60 / 40$ & $20 / 40$ \\
\hline Length $x$ Width $( \pm 0.2) \mathrm{mm}$ & $240 \times 190$ & $240.03 \times 190.02$ \\
\hline Central thickness* $( \pm 0.1) \mathrm{mm}$ & 20 & 20.01 \\
\hline Wedge (arcmin) & 1 & 0.43 \\
\hline
\end{tabular}

Table 2. HR-I prisms fabrication results.

\begin{tabular}{|c|c|c|}
\hline \multirow{2}{*}{$\begin{array}{c}\text { HR-I prism } 1 \\
\text { ID-426778 }\end{array}$} & \multirow[b]{3}{*}{ Requirement } & \multirow[b]{3}{*}{ Measuremen } \\
\hline & & \\
\hline Parameter & & \\
\hline \multicolumn{3}{|l|}{ Surface $A$} \\
\hline $\operatorname{RoC}(\mathrm{mm})$ & Flat & \\
\hline $\begin{array}{l}\text { Irr (P-V) in used aperture } \\
180 \mathrm{~mm} \times 140 \mathrm{~mm}\end{array}$ & $1 \mathrm{fr}$ & 0.5650 \\
\hline $\operatorname{Irr}(P-V)$ in $160 \times 150 \mathrm{~mm}$ & $0.5 \mathrm{fr}$ & 0.4731 \\
\hline MIL 13830 SD & $40 / 20$ & $40 / 20$ \\
\hline \multicolumn{3}{|l|}{ AR Coating $820-900 \mathrm{~nm}$} \\
\hline $\mathrm{AOI} 34.7^{\circ}$ & Tav & \\
\hline \multicolumn{3}{|l|}{ Surface B } \\
\hline $\mathrm{RoC}(\mathrm{mm})$ & Flat & \\
\hline $\begin{array}{l}\text { Irr }(P-V) \text { in used aperture } \\
200 \mathrm{~mm} \times 180 \mathrm{~mm}\end{array}$ & $2 \mathrm{fr}$ & 0.8153 \\
\hline $\operatorname{Irr}(\mathrm{P}-\mathrm{V})$ in $205 \times 160 \mathrm{~mm}$ & $1 \mathrm{fr}$ & 0.7960 \\
\hline MIL 13830 SD & $60 / 40$ & $60 / 20$ \\
\hline AR coating & no coating & - \\
\hline \multicolumn{3}{|l|}{ Angles } \\
\hline$A B$ & $68.61^{\circ} \pm 0.016^{\circ}$ & 68.50 \\
\hline BC & $42.39^{\circ}$ & 42.45 \\
\hline CA & $69^{\circ} \pm 0.1^{\circ}$ & 69.01 \\
\hline
\end{tabular}

\begin{tabular}{|c|c|c|}
\hline \multirow{2}{*}{\multicolumn{3}{|c|}{$\begin{array}{l}\text { HR-I prism } 2 \\
\text { ID-426778 }\end{array}$}} \\
\hline & & \\
\hline Parameter & Requirement & Measurement \\
\hline \multicolumn{3}{|l|}{ Surface A } \\
\hline $\mathrm{RoC}(\mathrm{mm})$ & Flat & \\
\hline $\begin{array}{l}\text { Irr }(P-V) \text { in used aperture } \\
180 \mathrm{~mm} \times 140 \mathrm{~mm}\end{array}$ & $1 \mathrm{fr}$ & 0.5730 \\
\hline $\operatorname{Irr}(\mathrm{P}-\mathrm{V})$ in $160 \times 150 \mathrm{~mm}$ & $0.5 \mathrm{fr}$ & 0.4528 \\
\hline MIL 13830 SD & $40 / 20$ & $40 / 20$ \\
\hline \multicolumn{3}{|l|}{ AR Coating $820-900 \mathrm{~nm}$} \\
\hline $\mathrm{AOI} 34.7^{\circ}$ & Tav & \\
\hline \multicolumn{3}{|l|}{ Surface B } \\
\hline $\operatorname{RoC}(\mathrm{mm})$ & Flat & \\
\hline $\begin{array}{l}\text { Irr }(P-V) \text { in used aperture } \\
200 \mathrm{~mm} \times 180 \mathrm{~mm}\end{array}$ & $2 \mathrm{fr}$ & 0.5961 \\
\hline $\operatorname{Irr}(\mathrm{P}-\mathrm{V})$ in $205 \times 160 \mathrm{~mm}$ & $1 \mathrm{fr}$ & 0.4477 \\
\hline MIL 13830 SD & $60 / 40$ & $40 / 20$ \\
\hline AR coating & no coating & _ \\
\hline \multicolumn{3}{|l|}{ Angles } \\
\hline$A B$ & $68.61^{\circ} \pm 0.016^{\circ}$ & 68.49 \\
\hline $\mathrm{BC}$ & $42.39^{\circ}$ & 42.48 \\
\hline CA & $69^{\circ} \pm 0.1^{\circ}$ & 68.97 \\
\hline
\end{tabular}


In Figure 8(a) a HR-I finished window is shown. Both surfaces were tested and verified. Figure 8(b) and 8(c) shows a HR-I prism with two surfaces polished.
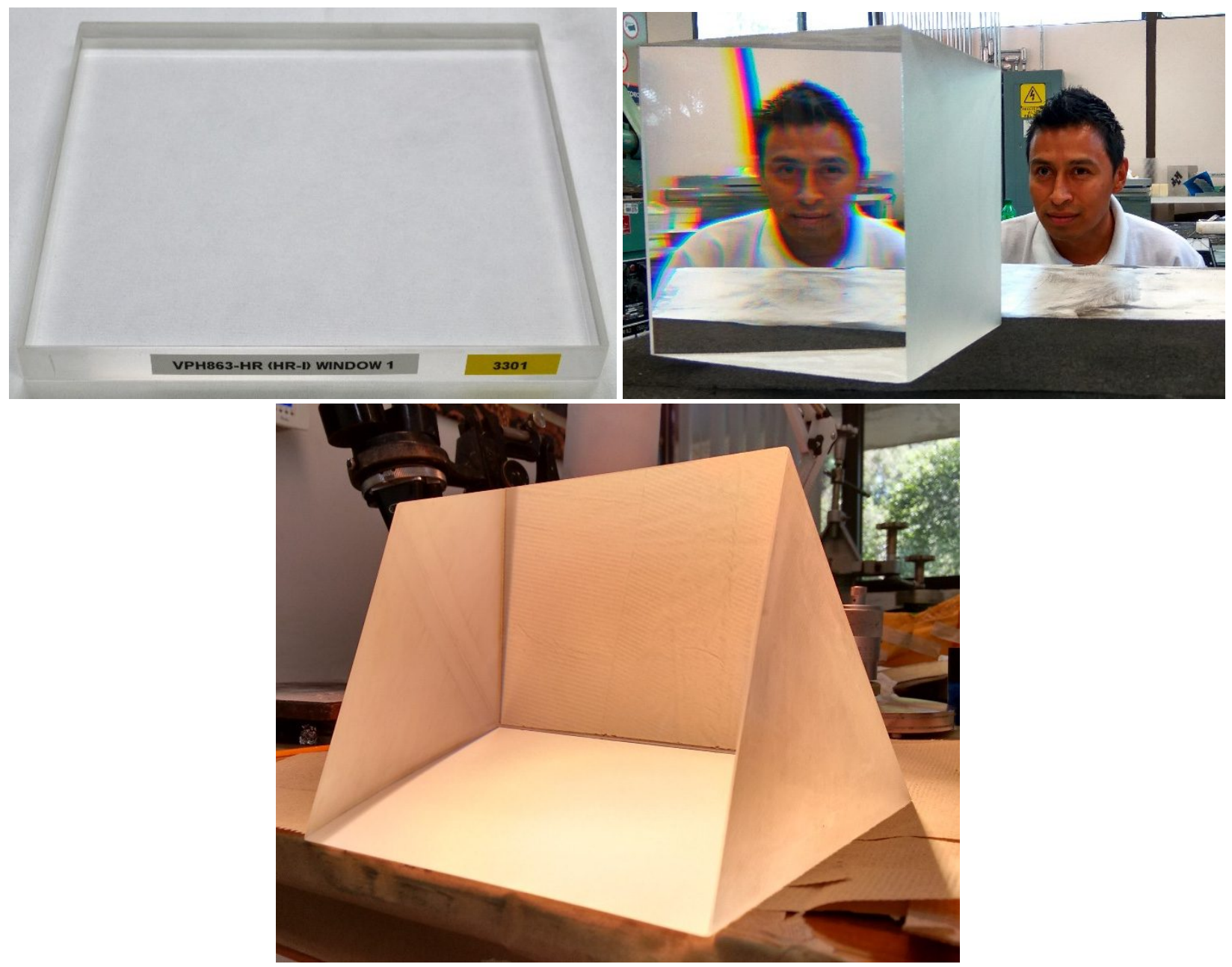

Figure 8. (a) Finished HR window. (b) Complete polishing of an MR prism. (c) Lateral view of the prism.

\section{CONCLUSIONS}

In this work we present the main operations to fabricate the MR/HR windows and MR prisms for MEGARA spectrograph, carried out at INAOE optical workshop. We have described the procedure followed to cut and to shape the flat surfaces of the windows and prisms. The prisms are mounted in an angular base made of cast iron. These bases have the correct angle to obtain parallelism between the surface to be polished and the base. Hot wax and UV curing adhesive are used for blocking the components. Overarm polishing machines are used in the grinding and polishing process. We have shown the optical tests used to verify the surface irregularity for windows and prisms. The techniques described here were applied to the LR, HR, MR windows and HR prisms and have successfully been used to achieve the very demanding specifications of MEGARA windows and prisms elements. 


\section{REFERENCES}

[1] Gil de Paz, A., et al., "MEGARA, the new intermediate-resolution optical IFU and MOS for GTC: getting ready for the telescope", Proc. of SPIE 9908, 9908-57 (2016).

[2] Carrasco, E., et al., "Performance of MEGARA spectrograph optical elements", Proc. of SPIE 9908, 9908304 (2016).

[3] Castillo, E., et al., "MEGARA main optics optomechanics", Proc. of SPIE 9147, 91475R (2014).

[4] Ferrusca, D., et al., "MEGARA cryostat advanced design", Proc. of SPIE 9147, 91476S (2014).

[5] Ortíz. R., et al., "Inverse analysis method to optimize the optic tolerances of MEGARA", Proc. of SPIE 9147, 914749 (2014).

[6] García-Vargas, M., et al., "Project management for complex ground-based instruments: MEGARA Plan", Proc. of SPIE 9150, 91500Y (2014).

[7] Pérez Calpena, A., et al., "System engineering at the MEGARA project”, Proc. of SPIE 9150, 915026 (2014). [8] Izazaga-Perez, R, et al, "Cutting and shaping operations for optical glasses", Proc. Of SPIE 9633, 963324 (2015).

[9] Karow, H., [Fabrication methods for precision optics], John Wiley \& Sons, New York, (1993). 